\title{
Mutual Health Insurance and Access to Care in the Health Zone of Kabinda, Kasaï-Oriental, Democratic Republic of Congo (DRC)
}

\author{
Cibangu Kazadi Richard1*, Bilonda Mpiana Alphonsine1, Kabengele Mpinga Emmanuel2, \\ Mulewu Ngandu Hippolyte3 ${ }^{3}$ Ciamala Mukendi Paul', Kanyiki Katala Moise5, \\ Kapitena Mangola Dominique1, Tshimungu Kandolo Félicien' ${ }^{6}$
}

\footnotetext{
${ }^{1}$ Department of Nursing, Higher Institute of Health Sciences of the Red Cross, Mbuji-Mayi, Democratic Republic of Congo ${ }^{2}$ Department of Community Health and Medicine, Faculty of Medicine, Institute of Global Health, University of Geneva, Geneva, Switzerland

${ }^{3}$ Department Nutrition Section of Nutrition and Dietetics, The Higher Institute of Medical Techniques of Mbuji-Mayi, Mbuji-Mayi, Democratic Republic of Congo

${ }^{4}$ Department of Education and Administration in Nursing, Nursing Section, The Higher Institute of Medical Techniques of Mbuji-Mayi, Mbuji-Mayi, Democratic Republic of Congo

${ }^{5}$ Department of Epidemiology, Division of Community Health, The Higher Institute of Medical Techniques of Mbuji-Mayi, Mbuji-Mayi, Democratic Republic of Congo

${ }^{6}$ Department of Public Health, Epidemiology, Policy and Health System Division of Community Health, The Higher Institute of Medical Technologies, Kinshasa, Democratic Republic of Congo

Email:*cibangurichard@gmail.com
}

How to cite this paper: Richard, C.K., Alphonsine, B.M., Emmanuel, M.K., Hippolyte, M.N., Paul, C.M., Moise, K.K., Dominique, K.M. and Félicien, T.K. (2017) Mutual Health Insurance and Access to Care in the Health Zone of Kabinda, KasaiOriental, Democratic Republic of Congo (DRC). Open Access Library Journal, 4: e3568.

https://doi.org/10.4236/oalib.1103568

Received: March 28, 2017

Accepted: April 24, 2017

Published: April 28, 2017

Copyright $\odot 2017$ by authors and Open Access Library Inc.

This work is licensed under the Creative Commons Attribution International License (CC BY 4.0).

http://creativecommons.org/licenses/by/4.0/

\begin{abstract}
In the Democratic Republic of Congo, a large part of the population now lives in a context of extreme poverty and suffers from serious health problems. Deprived of social protection, these people see themselves therefore in the financial inability to access quality health care. This study aims to analyze the different characteristics of members of the mutual health insurance and compare with non-members. The following observations were made: Of those surveyed, $97.7 \%$ and $91.4 \%$ of members were not members resorted average 4 times to health services during the last 6 months prior to the survey, a statistically significant difference was observed $(\mathrm{p}=0.027)$. The survey data showed that a significant proportion of members and non-members $(62.5 \%$ vs $66.4 \%$; $\mathrm{p}=0.36)$ had resorted to self-medication. For non-members, the rate of selfmedication and traditional therapy were higher. Lack of money is mentioned by members and non-members as a problem limiting access to health care $(38.3 \%$ vs $69.5 \%$; $<<0.0001)$.
\end{abstract}

\section{Subject Areas}

Infectious Diseases 


\section{Keywords}

Membership, Mutual Health, Access to Care, Rural Kabinda

\section{Introduction}

A population that is healthy is better able to contribute to socio-economic development of a country. This is ensured by healthy developmental milestones such as good nutrition, hygiene, healthy environment and also access to quality health care. Yet nearly half of the world population has no access to basic health care. This is also true for the Kasai Oriental province in general and Kabinda health zone in particular.

Several studies have examined the issue of mutual health in sub-Saharan Africa. However, no similar studies have been conducted in rural Africa, especially south of the Sahara, to show the health financing mechanisms [1] [2] [3].

In most African countries in south of the Sahara, where incomes are among the lowest in the world, the health financing mechanisms are dominated by the direct payment of households in time of need. This is the oldest form of the market for private care without insurance, devoid of solidarity, fairness and in which only the patient participates [4] [5].

Nearly half of the world population has no access to basic health care. This is also true for the Democratic Republic of Congo (DRC). According to the Demographic and Health Survey, the rate of access to health care is between $40 \%$ and $50 \%$.

Clearly, more than 30 million Congolese(s) do not have access to quality health care [6].

In low-income countries, health insurance is a response to the problem of access to care and financial protection for those excluded from formal insurance systems, mainly the working poor in the informal sector.

At present, several clues in the Democratic Republic of Congo indicate that the distribution of the budget is not respected, and health has not received adequate funding strategies [7]. The funding gap is now the basis for performance-cons. If before independence risk disease was provided by the state, so far it would be almost non DRC in general and Kasai Oriental in particular.

The Kasai Oriental Province in its former configuration is divided into 51 Health Zones, and only the Kabinda Health Zone has a functional mutual health benefiting from the support of the CAP-Health Non-Profit Association whose head office is in the Province of Liège in Belgium. However, the members or members of this health insurance company reside or work in Kabinda. Those who are not members of the Kabinda Mutual Health Society (MSK), when a health problem arises, take into account their financial means to the traditional medicine to self-medication or they will consult the pastors who they pray for to regain health.

MSK is community-based. The amount of annual fee is set at US \$6 per 
member. Members of the Mutual pay a co-payment of $20 \%$ in hospitalization and $50 \%$ in outpatient treatment. At the health center and referral hospital, the MSK supports the rest of the bill members. The mutual health insurance covers the following services: preventive care (antenatal, immunization), curative care (consultations, accommodation at the health center, hospital, nutritional rehabilitation), the eutocic and obstructed labor, cesarean section, laboratory tests, and surgery whether minor or major.

All these situations lead us to conduct a study that will answer the following questions:

1) What are the socio-economic and health characteristics of members and non-members of the mutual?

2) Do members have greater access to health care and under what conditions?

3) What is the level of adherence to mutual health?

The ultimate goal of the study is to contribute to the promotion of risk-pooling systems as a tool to improve financial accessibility to quality care.

\section{Material and Methods}

The survey was conducted from June 25 to July 10, 2014 in Kabinda health zone. Six investigators upper secondary level trained for 20 hours in investigation techniques, the questionnaire administered under the supervision of a research team.

To get to draw the sample of this study, we made use of probability sampling, especially the systematic random sample, with the spike data 7 software in his stat calc menu, from population 1768 mutual, with the $95 \%$ confidence interval, the frequency of $10 \%$ a sample drawn is 128 mutualistic. This sample is to be selected in the lists of members of the mutual health. Witnesses, 128 not members of the MHO are close mutualistic, giving a sample of 256 people.

The questionnaire was pre-tested, tweaked, refined, validated and administered to 256 households with 128 members (members) of the MSK and 128 non-members (non-members). Several variables were used in this study: socio-economic and demographic variables (age, gender, household size, household income, cost of care, occupation, family status, sources of funding to pay for membership in the mutual, household spending for health care), sociocultural variables (education), geographic variables (distance, means of transport), organizational variables (quality of care), variables concerning medical history, gynecological obstetric and surgical.

The questionnaire was sent directly to the heads of households by the investigator who administered it.

The questions were closed and coded, except those related to earlier disease state were semi-closed and encoding was done at the count of responses. The administration time of the survey averaged 25 minutes for each household.

The study was carried out with the agreement of the provincial ethics committee, local authorities and the relevant authorities of the mutual. After an oral, free and informed consent, all subjects had responded to the survey and agreed to participate in the study. 
The survey data were entered, checked and analyzed on Epi Info 7 software and SPSS for Windows (Version 12). Statistical analyzes were performed with the same software. Chi-square Pearson test was used to compare proportions of the different variables used between members and non members. With an $\alpha$ risk of $5 \%$, any value of $\rho<0.05$ probability was considered significant.

\section{Results}

\subsection{Demographics of Members and Non-Members}

The survey involved 256 people (128 members/members and 128 non-members/non-members). Of the 128 members surveyed, there were $62.5 \%$ men and $37.5 \%$ women against $66.4 \%$ men and $33.6 \%$ women. The gender distribution was not significantly different between members and non-members $(\mathrm{p}=0.513)$. The sex ratio was $1.7 / 1$ to $2 / 1$ against members for non members.

The majority of members and non-members $(71.2 \%$ vs $76.5 \%)$ were active people, whose age range was between 19 and 49 years. The average age of members and non-members was 36 years vs 37.3 years (SD: 13.2 years vs. 4.9 years) with extreme values of 19 to 84 years (Table 1 ).

The majority of member households $(74.2 \%$ vs $76.6 \%$; $=0.02)$ were married. The average household size was 4.6 people vs people 5.8 (SD: 3.4 vs 9.4). Households large ( $>5$ persons) more adhere to the mutual. The survey data showed that $67.2 \%$ of members and $68 \%$ of non-members belonged to households very large ( $>5$ persons). Household size was not significantly different between members and non-members to mutual ( $p>0.05)$.

The estimated average monthly income based on total daily household expenses for the purchase of food, was US $\$ 45$ for members and $\$ 43$ US for non-members with extreme values of $\$ 30$ to $\$ 150$. With an average household size of 5 people, average income attested that each respondent spent US $\$ 0.3$ (under $\$ 1$ ) a day for food, reflecting the extreme poverty of the populations surveyed.

Of the 128 members, $98.4 \%$ against $89.1 \%$ non-members had a high level of education (secondary and higher), $1.6 \%$ of participants against $11 \%$ of nonmembers had a low level of education (without primary level and level). The difference is significant between members and non-members $(p=0.007)$.

Of the 128 members, officials represented $55.5 \%$ against $30.4 \%$, farmers $25 \%$ against $31.3 \%$. The distribution by occupation significantly differs between members and non-members $(\mathrm{p}=0.0003)$.

\subsection{Membership Mutual and Disease Status}

Table 2 below shows that of those surveyed, $97.7 \%$ and $91.4 \%$ of members are not members resorted average 4 times to health services during the last 6 months before the survey, statistically significant difference was observed $(p=0.027)$. Adherents to mutual attend more primary care health centers, they spend less than non-members for health care, they pay a co-payment of $20 \%$ in hospitalization and $50 \%$ of total expenditure on outpatient treatment. Regarding the reasons 
Table 1. Demographics of members and non-members to Kabinda MHO.

\begin{tabular}{|c|c|c|}
\hline Characteristics & Members $(\mathrm{N}=128)$ & Members $(\mathrm{N}=128)$ \\
\hline \multicolumn{3}{|l|}{ Sex } \\
\hline Male & 62.5 & 66.4 \\
\hline Female & 37.5 & 33.6 \\
\hline \multicolumn{3}{|l|}{ Age group } \\
\hline$<20$ years & 3.9 & 2.3 \\
\hline $20-49$ & 67.3 & 74.2 \\
\hline$>49$ years & 28.9 & 23.4 \\
\hline \multicolumn{3}{|l|}{ Marital status } \\
\hline Singles & 18 & 10.2 \\
\hline Married(s) & 74.2 & 76.6 \\
\hline Other & 7.9 & 13.3 \\
\hline \multicolumn{3}{|l|}{ Household size } \\
\hline$<5$ people & 32.8 & 32 \\
\hline$>5$ people & 67.2 & 68 \\
\hline \multicolumn{3}{|l|}{ Level of education } \\
\hline No level/Primary & 1.6 & 11 \\
\hline Secondary & 62.5 & 61.8 \\
\hline University & 35.9 & 27.3 \\
\hline \multicolumn{3}{|l|}{ Profession } \\
\hline Officials & 55.5 & 30.4 \\
\hline Private sector worker & 7 & 15.6 \\
\hline Tradespeople & 5.5 & 10.2 \\
\hline Farmers & 25 & 31.3 \\
\hline \multicolumn{3}{|l|}{ Returned } \\
\hline$<$ US $\$ 100$ & 92.2 & 82 \\
\hline US $\$ 100-150$ & 7 & 13.3 \\
\hline$>$ US $\$ 150$ & 0.8 & 4.7 \\
\hline
\end{tabular}

$\mathrm{n}=$ number of members and non-members included in the study.

why to join the mutual, $72.3 \%$ of non-members bind accession to reducing the cost of care, $18.4 \%$ to quality care and $9.3 \%$ decreased risk of complications disease.

The survey data shows that a significant proportion of members and non-members $(62.5 \%$ vs $66.4 \% ; \mathrm{p}=0.36)$ have resorted to self-medication. Traditional therapy is a type of treatment prescribed by a healer remains unused use by households, it does not reach $15 \%$ (10.9\% vs $14.1 \%)$. For non-members, the rate of self-medication and traditional therapy were higher. Lack of money is mentioned by members and non-members as a problem limiting access to health care $(38.3 \%$ vs $69.5 \%$; $\mathrm{p}<0.0001)$.

The proportions of the medical history among members and non-members are $37.2 \%$ vs $21.3 \%$ ( $\mathrm{p}<0.05)$. Regarding gynecology obstetric history, the proportions are $12.3 \%$ vs. $7.9 \%$. Surgical history were rare and were presented with 
Table 2. Adherence to the mutual and disease state.

\begin{tabular}{ccc}
\hline Characteristics & Members (N = 128) & Members (N = 128) \\
\hline Therapeutic use & & \\
\hline Health centers & 97.7 & 91.4 \\
Self-medication & 62.5 & 66.4 \\
Folk medicine & 10.9 & 14.1 \\
\hline Barriers to access to health care & & 69.1 \\
\hline Money & 38.3 & 7 \\
Distance & 9.4 & 3.2 \\
Quality of care & 4.7 & 83.5 \\
\hline Wish to join the mutual & & \\
\hline Yes & N/A & 72.5 \\
\hline Reasons for membership & & 9.3 \\
\hline Care cost reduction & N/A & 18.4 \\
Reduced risk of complications & N/A & \\
Quality Care & N/A & 21.3 \\
\hline antecedents & & 7.9 \\
\hline Medical background & 37.2 & \\
Gynecologic Obstetric history & 12.3 & \\
Surgical history & 8.6 & \\
\hline
\end{tabular}

$\mathrm{NA}=$ not applicable to this group.

low levels (8.6\% vs 5.3\%). Finally for surgical history it was any surgery, appendicitis, hernia, osteosynthesis, myomas, etc. The appendectomy rate was $0.8 \%$ vs. $2.3 \%$ in both groups.

The medical history were considered malaria, diarrhea, respiratory diseases, gastritis, measles, meningitis, tuberculosis, rheumatoid arthritis, intestinal parasites and diabetes. In the population of members and non members, $60.9 \%$ vs $45.2 \%$ ( $\mathrm{p}=0.01$ ) reported having suffered from malaria; $25 \%$ vs $18.8 \%$ of respiratory diseases and $14.8 \%$ vs $23.4 \%$ of gastritis.

In terms of gynecological obstetric history, we identified childbirth, abortion, genital infections, birth of a stillborn, and cesarean section. In the population of members, the delivery rate was $4.7 \%$ and $2.4 \%(\mathrm{p}<0.05)$ from the group of non-adhering, the CS rate was $0.8 \%$ among members.

\section{Discussion}

Spending that causes the disease can not be predicted nor as to their amount or to the period they are incurred. The existence of a functioning health system is one of the essential conditions, not only to achieve the Millennium Development Goals, but also and especially to reduce the human suffering of the most vulnerable. It is in this view that the mutual health improves people's access to quality health care.

It should be noted first that the subjects in this study have demographics sim- 
ilar to those already noted in other works: a male predominance among members and non-members (62.5\% vs $66.4 \%)$ with a sex ratio greater than 1.5 for men, a majority of subjects from 20 to 49 years corresponding to the working population, a significant proportion of married $(74.2 \%$ vs. $76.6 \%)$ among respondents. These authors indicate that age seems not to exert influence, younger as older, never being under or over-represented among members [1] [2] [8].

The Kabinda health area is one of the rural areas and most of the population is engaged in agriculture. The largest occupational groups for the 2 groups: $55.5 \%$ vs $30.4 \%$ officials and farmers $25 \%$ vs. $31.3 \%$. The salary (the salary of civil servants is very low in the DRC, on average US $\$ 50$ per month) and agriculture are the two main sources of income for households. Other professional groups (the private sector workers, traders, diamond diggers) represented proportions of less than $7 \%$.

The results of Carrin G. [9] showed that in rural areas, irregular incomes are dominant, while in urban areas there is a higher prevalence of daily income (45.73\% of urban households) and monthly (41.08\% of urban households) [9].

Household size has been categorized into two groups, depending on the average household size Kasai (5.2 persons). The average size was high, it was higher for non-members than for members. This observation confirms the results of previous work by the Ministry of Public Health of the Democratic Republic of Congo and elsewhere Soglohoun P., indicates that the size of households has influence on registration mutual because the more household size is, the more people have difficult access to health services [10] [11].

Poverty engendered a very large size of households is reflected in the non- satisfaction of basic needs. It does not mobilize financial resources to the needs for food, health and housing of its members, or to offer them an education that determines the level of education and literacy, which in turn determines the knowledge, self-making and openness to innovation [12] [13] [14].

Income and its distribution within the population and in the household are the most decisive feature for family health. In this study, the average household monthly incomes are low, see zero. The average monthly income of households calculated based on daily expenditure per person for food are US $\$ 45$ for members and $\$ 43$ US for non-members for a household of 5 people on average.

Data from the World Bank (1984) based on the income and expenditure of households, establishes an association between poverty and many descendants. Considering the poverty line of US $\$ 1$ per day per person, members and non-members living in extreme poverty (spending on food per day per person amounted to US $\$ 0.30$ [15].

The study by Mususa I., Tangoma K. and Tshimungu K. found similar results. A broad consensus among the various studies points out that the lack of financial resources is the main reason given by households to explain their non-participation in a mutual health [16] [17].

The study shows that the proportion of respondents with low levels of education and literacy are higher for non-members. These results are similar to data 
Mushagalusa [14].

As first choice during six months preceding the survey, members and non-members on average have been four times (4) use of health services. In non recourse to self-medication and traditional therapy as the first choice was more common. These results support the observations according to which, for nonmembers, the self-medication or traditional healers as their first choice was more common [18].

Malaria remains the pathology encountered among members as among non-participants ( $60.5 \%$ vs $45.2 \%)$, followed by acute respiratory infections ( $25 \%$ vs $18.8 \%)$. The difference is significant $(\mathrm{p}=0.012)$. These observations support the results of previous work in the DRC and elsewhere by Ilunga IF et al. [19] and Christopher JL, et al. [20] according to which, on the African continent greatly exposed, malaria is the leading cause of morbidity and mortality, it greatly contributes to underdevelopment and poverty, and introduces so a major obstacle to socioeconomic development.

It has been estimated that malaria costs Africa more than 12 billion US dollars each year. Malaria kills more than 500,000 so individuals in endemic areas each year, children under 5 years being the most affected. Tropical or subtropical Africa has more than $80 \%$ and $90 \%$ mortality. Moreover, if we consider the indirect effects of malaria and its manifestations correlated with other diseases, the number of deaths would be even more important than that communicated each year [19].

Our results show that the members of the mutual attend more health centers in primary care, but they spend less on health care. Non-members attending more traditional practitioners and practice more self-medication. The ease of access to health care allows mutual ready access and the best time for these services long before the disease worsens; minimizing expenses mutualist.

Our study shows that non-members are pledging or selling a material good for health care. The health insurance system has a positive impact on costs of care of members of the mutual, their health and perhaps even on the household economy [21].

As Musango, in addition to lack of money as a big obstacle, our study identified other factors as the basis for non-adherence to mutual health: the non-involvement of local authorities and opinion leaders to start. Their membership could help convince people of the importance of mutual health [18].

Awareness should primarily target local authorities and opinion leaders whose accession could have a mobilizing effect. Some countries have set up mutual health, develop strategies to facilitate the accession of the poor payment of the premium in small installments for 6 months or a payment of dues by several spread slices (Project PRIMA Guinea Conakry). Sometimes contribution benefits are granted to mutual reducing the cost for many families and support a number of the poor. At the Mutual Health Kabinda in Kasai-Oriental (DRC), the amount of annual fee is set at US $\$ 6$ per member. In Rwanda, the amount of contribution is set at 7.9 US $\$$ per year for a family of 7 and US $\$ 5.7$ for a single [22]. 


\section{Conclusion}

Improvement of the use of health services remains a priority for the DRC. Despite a considerable increase in the number of health centers and hospitals, attendance as the cost of health care has not changed at all, and access to health care remains a busting head for families.

In order to improve knowledge on this pressing issue, we conducted a retrospective survey, quantitative during 2014 in Kabinda health zone, Kasai Oriental Province in the old configuration, DRC. Some data from our research had to appeal to the memory of interviewees; we were not spared from the systematic error due to differences in the accuracy and completeness of the reminder to the memory of events and past experiences. This could constitute a memory bias. After analyzing the data collected, it is accepted today that we must educate various officials (national and provincial ministries of health) and foster public support for mutual health insurance.

In this study, regarding the financing of contributions to Kabinda MHO there are two main sources. First, there is the financing from own resources of members, and secondly, a third-party financing. MSK receives financial support of the NPO CAP Health-paying permanent monthly subsidies. Unfortunately these subsidies are very low. The results of the study show that members and nonmembers have a very low average income, they live in extreme poverty.

However, mutual demonstrating great flexibility in sampling and frequency of contributions and in terms of membership would generate more community participation.

\section{Limits of the Study}

Throughout our research, we were stubborn to the material order of difficulty in terms of time and financial resources to manage to reach the subjects of investigation, and some addresses found in the register do not specify the place of residence, the distances to go to reach the surveys were enormous. Scientifically, our study was limited to the organization of a mutual health and access to care for the population of the ZS Kabinda.

\section{Conflicts of Interest}

We declare that there is no conflict of interest.

\section{Author Contributions}

All authors contributed to the writing and editing of the manuscript.

\section{References}

[1] Defourny, J. and Failon, J. (2011) Determinants of Adherence to Mutual Health Insurance in Sub-Saharan Africa: An Inventory of Empirical Work.

[2] Waelkens, M.-P. and Criel, B. (2004) The Mutual Health Organizations in Sub-Saharan Africa: Overview and Reflections on a Research Agenda. PST Discussion Paper. 
[3] Musango, L., Bruno, D., Michele, D. and Criel, B. (2004) The Profile of the Members and Non-Members of Mutual Health Insurance in Rwanda: The Case Kabutare Health District. Tropical Medicine and International Health, 9, 1222-1227. https://doi.org/10.1111/j.1365-3156.2004.01318.x

[4] World Health Organization (2000) The World Health Report 2000: Health Systems-Improving Performance. World Health Organization, Geneva.

[5] Gottret, P. and Schieber, G. (2007) Financing Health: A New Approach-A Guide for Policy Makers and Practitioners. World Bank, Editions Saint Martin.

[6] Democratic Republic of Congo. Ministry of Planning-Ministry of Health (2009) Survey Demographic and Health Survey (DHS-RDC, 2009). Analysis Report, Kinshasa.

[7] National Institute of Statistics (2007). Report-Synthesis on Demographic Projections. NIS, Kinshasa.

[8] Boyege, I. (2005) Contribution of Mutual Health Accessibility of the Population to Health Services. National University of Rwanda, Rwanda.

[9] Carrin, G. (2002) Social health Insurance in Developing Countries: A Continuing Challenge. International Social Security Review, 55, 73-89. https://doi.org/10.1111/1468-246X.00124

[10] Ministry of Public Health (2011) Cluster Survey MICS Multiple Indicator 2010. Final Report Kasaï-Oriental, September 2011.

[11] Soglohoun, P. (2012) Contribution of Mutual Health Organization to Demand Services and Health Care in the DRC. Health Systems 20/20 Project, Abt Associates Inc., Bethesda.

[12] Caldwel, A.D. (1989) Education as a Factor in Mortality Decline: An Examination of Nigeria Data. Population Studies, 33, 395-415. https://doi.org/10.2307/2173888

[13] Ministry of Planning, UNICEF (2002) National Survey on the Situation of Children and Women (MICS 2) in the DRC in the DRC in 2001. Analysis Report, Kinshasa, $221 \mathrm{p}$.

[14] Mushagalusa, S. (2005) Study of Determinants of the Use of Health Services in the Kadutu Health Zone, South Kivu, DRC. Kinshasa University, Kinshasa.

[15] World Bank (1984) Report on World Development 1984. World Bank, Washington DC.

[16] Mususa, I. and Tangoma, K. (1994) Crisis and Adjustment of Kinshasa Households: 1975-1993. Conjuncture Note 13, 18-24.

[17] Tshimungu, K. (2010) Contribution to the Study of the Determinants of the Resurgence of Human African Trypanosomiasis in Kinshasa. PhD Thesis, Faculty of Medicine, University of Liège, Liege.

[18] Musango, L., Bruno, D., Michele, D. and Criel, B. (2004) The Profile of the Members and Non-Members of Mutual Health Insurance in Rwanda: the Case Kabutare Health District. Tropical Medicine and International Health, 9, 1222-1227. https://doi.org/10.1111/j.1365-3156.2004.01318.x

[19] Ilunga, I.F., Levêque, A., Okenge, N.L., Tshimungu, K.F. and Dramaix, M. (2014) Costs of Treatment of Children Affected by Severe Malaria in Reference Hospitals of Kinshasa, Democratic Republic of Congo. Journal of Infection in Developing Countries, 8, 1574-1583. https://doi.org/10.3855/jidc.4622

[20] Murray, C.J., et al. (2012) Global Malaria Mortality Entre 1980 and 2010: Systematic Analysis. Lancet, 379, 413-431. https://doi.org/10.1016/S0140-6736(12)60034-8

[21] Barth, C. (1998) District-Based Health Insurance in Sub-Saharan. Part I: From 
Theory to Practice in: Studies in Health Services Organization and Policy, 9. ITG Press, Antwerpen, Belgium, 31-42.

[22] The PRIMA Project in Guinea Conakry (2002) Study of the Social Perception of Community Mutual Maliando Health Area. In: Criel, A.N. and Barry Von Roenne, F., Eds., A Mutual Health Organization Experience in Rural Medicus Mundi Belgium, Brussels, 121-206.

Submit or recommend next manuscript to OALib Journal and we will provide best service for you:

- Publication frequency: Monthly

- 9 subject areas of science, technology and medicine

- Fair and rigorous peer-review system

- Fast publication process

- Article promotion in various social networking sites (LinkedIn, Facebook, Twitter, etc.)

- Maximum dissemination of your research work

Submit Your Paper Online: Click Here to Submit

Or Contact service@oalib.com 